\title{
Erratum zu: Die verborgene Politik des impliziten Wissens: Michael Polanyis Republik der Wissenschaft
}

\author{
Frank Fischer $\cdot$ Alan Mandell
}

Erratum zu: Fischer, F. et al. (2009) Die verborgene Politik des implizierten Wissens: Michael Polanyis Republik der Wissenschaft. Leviathan 37(4):519-531 DOI 10.1007/s11578-009-0059-9

Dieser Beitrag wurde von Marianne Wagner übersetzt.

(c) VS-Verlag 2010

Die Onlineversion des Originalbeitrages ist ereichbar unter doi:10.1007/s11578-009-0059-9

Prof. Dr. F. Fischer $(\bowtie)$

Rutgers University, Newark, N.J., USA

E-Mail: ffischer@rutgers.edu

Prof. Dr. A. Mandell

Empire State College, State University of New York, New York, USA

E-Mail: Alan.Mandell@esc.edu 